\title{
Electric Motor Drive Selection Issues for HEV Propulsion Systems: A Comparative Study
}

\author{
Mounir Zeraoulia, Student Member, IEEE, Mohamed El Hachemi Benbouzid, Senior Member, IEEE,
} and Demba Diallo, Senior Member, IEEE

\begin{abstract}
This paper describes a comparative study allowing the selection of the most appropriate electric-propulsion system for a parallel hybrid electric vehicle (HEV). This paper is based on an exhaustive review of the state of the art and on an effective comparison of the performances of the four main electricpropulsion systems, namely the dc motor, the induction motor (IM), the permanent magnet synchronous motor, and the switched reluctance motor. The main conclusion drawn by the proposed comparative study is that it is the cage IM that better fulfills the major requirements of the $\mathrm{HEV}$ electric propulsion.
\end{abstract}

Index Terms-Comparison, electric propulsion, hybrid electric vehicle (HEV).

\section{INTRODUCTION}

$\mathbf{S}$ ELECTION of traction motors for hybrid propulsion systems is a very important step that requires special attention. In fact, the automotive industry is still seeking for the most appropriate electric-propulsion system for hybrid electric vehicles (HEVs) and even for EVs. In this case, key features are efficiency, reliability, and cost. The process of selecting the appropriate electric-propulsion systems is, however, difficult and should be carried out at the system level. In fact, the choice of electric-propulsion systems for HEVs mainly depends on three factors: driver expectation, vehicle constraint, and energy source. With these considerations, it is obvious that the overall motor operating point is not tightly defined [1]. Therefore, selecting the most appropriate electric-propulsion system for a HEV is a challenging task.

In an industrial point of view, the major types of electric motors adopted or under serious consideration for HEVs as well as for EVs include the dc motor, the induction motor (IM), the permanent magnet (PM) synchronous motor, and the switched reluctance motor (SRM) [2]. Cross sections of each of these four motor types are provided in Fig. 1.

Moreover, based on an exhaustive review of the state of the art related to electric-propulsion systems, it is observed that investigations on the cage IMs and the PM motors are highly dominant, whereas those on dc motors are decreasing,

Manuscript received June 23, 2005; revised December 22, 2005, and January 21, 2006. The review of this paper was coordinated by Prof. A. Emadi.

M. Zeraoulia and M. E. H. Benbouzid are with the Laboratoire d'Ingénierie Mécanique et Electrique (LIME), Electrical Engineering Department, IUT of Brest, University of Western Brittany, 29231 Brest Cedex 3, France (e-mail: m.zeraoulia@ieee.org; m.benbouzid@ieee.org).

D. Diallo is with the Laboratoire de Génie Electrique de Paris (LGEP) CNRS UMR 8507, University of Paris XI, Supélec, 91192 Gif-Sur-Yvette, France (e-mail: ddiallo@ieee.org).

Color versions of Figs. 1, 2, 4, 5, 8, 11, 13, 17, and 18 and Tables I and II are available online at http://ieeexplore.iee.org.

Digital Object Identifier 10.1109/TVT.2006.878719

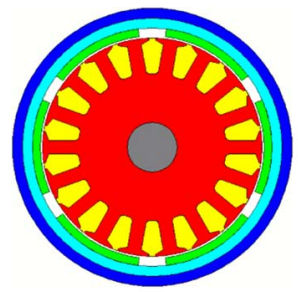

(a)

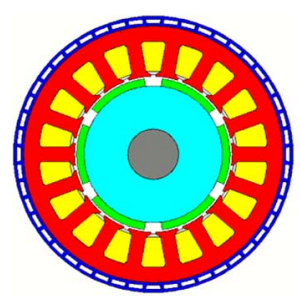

(c)

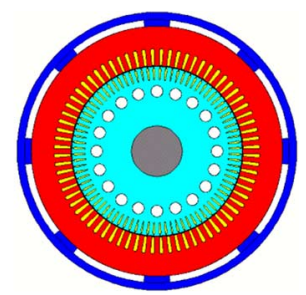

(b)

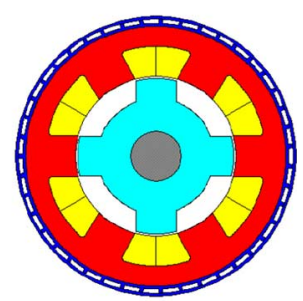

(d)
Fig. 1. Industrial and traction motors. (a) DC motor. (b) IM. (c) PM brushless motor. (d) SRM.

and those on switching reluctance motors are gaining much interest [3]-[6].

In this paper, potential candidates for the traction motor, for parallel HEVs, are presented and evaluated according to the major requirements of a $\mathrm{HEV}$ electric-propulsion system. Conclusions are then drawn to identify the most potential candidate of traction motor for parallel hybrid propulsions.

\section{HEV MAJOR REQUIREMENTS}

\section{A. HEV Configuration}

The proposed comparative study has been done on the parallel HEV configuration (Fig. 2). In fact, by being different from the series hybrid, the parallel HEV allows both the internal combustion engine (ICE) and the electric motor to deliver power in parallel to drive the wheels. Since both the ICE and the electric motor are generally coupled to the drive shaft of the wheels via two clutches, the propulsion power may be supplied by the ICE alone, by the electric motor, or by both. Conceptually, it is inherently using an electric-assisted ICE for achieving lower emissions and lower fuel consumption.

Better than the series HEV, the parallel hybrid needs only two propulsion devices; they are the ICE and the electric motor. Another advantage over the series case is that a smaller ICE and a smaller electric motor can be used to get the same performance until the battery is depleted. Even for a long-trip operation, only the ICE needs to be rated for the maximum 


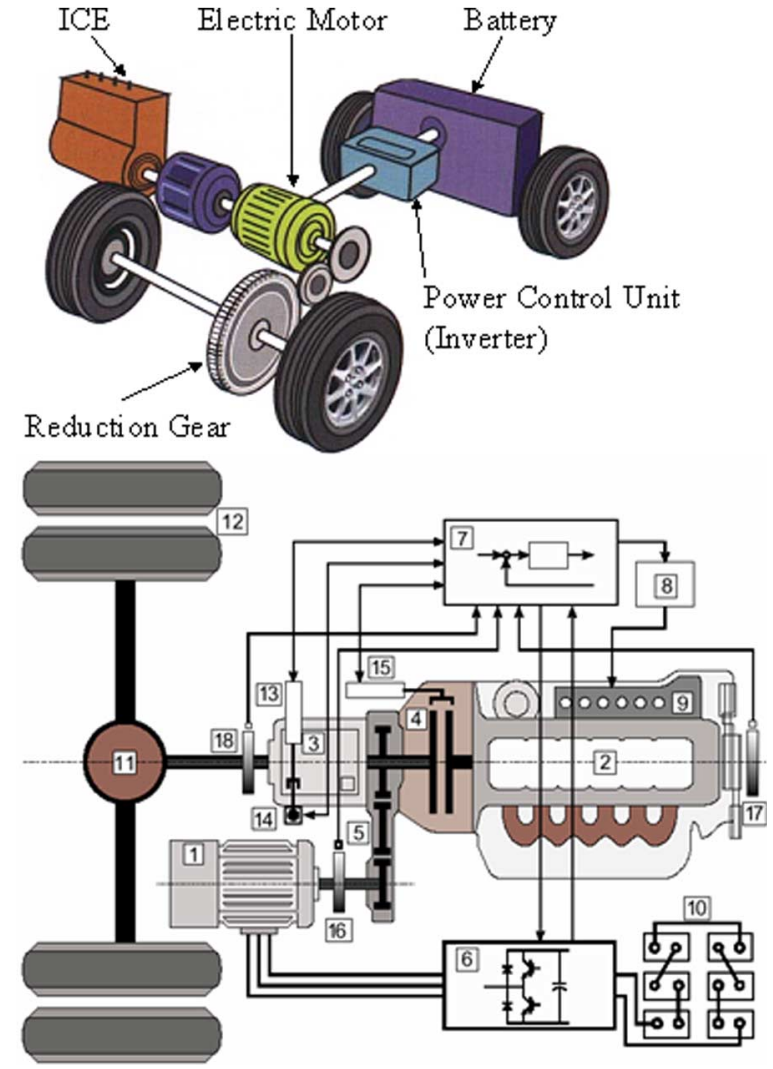

Fig. 2. HEV parallel configuration. 1. Electric motor, 2. ICE, 6. Inverter, 7. Controller, 10. Battery, 11. Differential gear.

sustained power, while the electric motor may still be about a half [3], [7].

Sizing the electric motor is a key point in a HEV to improve fuel economy and for dynamic performances. The ratio between the maximum power of the electric motor $\left(P_{\mathrm{EM}}\right)$ and the ICE $\left(P_{\mathrm{ICE}}\right)$ is characterized by the hybridization factor $(\mathrm{HF})$ that is defined as

$$
\mathrm{HF}=\frac{P_{\mathrm{EM}}}{P_{\mathrm{EM}}+P_{\mathrm{ICE}}}=\frac{P_{\mathrm{EM}}}{P_{\mathrm{HEV}}}
$$

where $P_{\mathrm{HEV}}$ is the maximum total traction power to propel the HEV. It has been demonstrated that hybridization improves HEV fuel economy and dynamic performances up to a critical optimum point $(\mathrm{HF}=0.3$ to 0.5$)$. After this point, increasing the electric-propulsion system capacity will not improve the HEV performances [8], [9].

\section{B. Motor Characteristics Versus Electric Traction Selection}

The major requirements of HEVs electric propulsion, as mentioned in past literature, are summarized as follows [1], [3]:

1) a high instant power and a high power density;

2) a high torque at low speeds for starting and climbing, as well as a high power at high speed for cruising;

3) a very wide speed range, including constant-torque and constant-power regions;

4) a fast torque response;

5) a high efficiency over the wide speed and torque ranges;

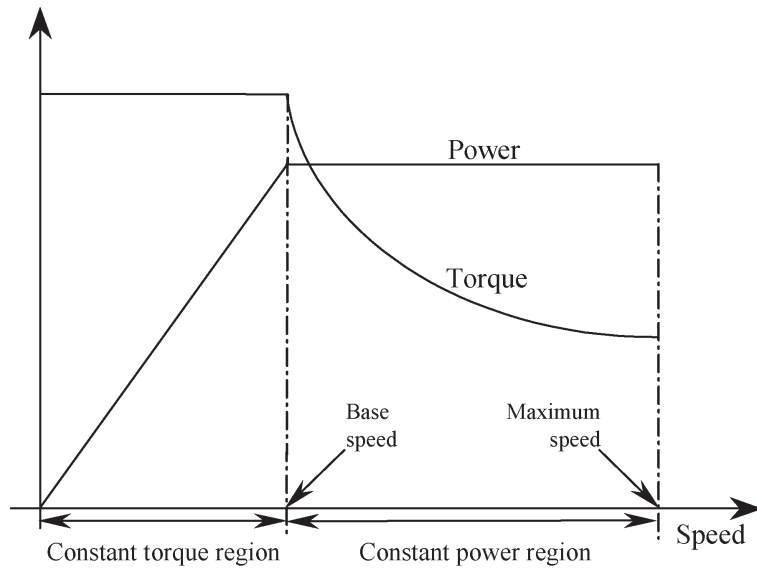

(a)

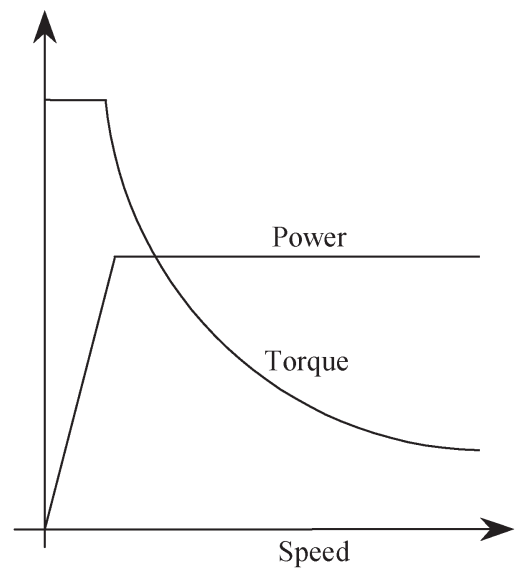

(b)

Fig. 3. HEV typical characteristics. (a) Electric traction. (b) Tractive effort versus the speed.

6) a high efficiency for regenerative braking;

7) a high reliability and robustness for various vehicleoperating conditions; and

8) a reasonable cost.

Moreover, in the event of a faulty operation, the electric propulsion should be fault tolerant [10], [11]. Finally, from an industrial point of view, an additional selection criterion is the market acceptance degree of each motor type, which is closely associated with the comparative availability and cost of its associated power converter technology [4].

Fig. 3(a) illustrates the standard characteristics of an electric motor used in EVs or HEVs. Indeed, in the constant-torque region, the electric motor exerts a constant torque (rated torque) over the entire speed range until the rated speed is reached. Once it is past the rated speed of the motor, the torque will decrease proportionally with speed, resulting in a constantpower (rated power) output. The constant-power region eventually degrades at high speeds, in which the torque decreases proportionally with the square of the speed. This characteristic corresponds to the profile of the tractive effort versus the speed on the driven wheels [Fig. 3(b)]. This profile is derived from the characteristics of the power source and the transmission. Basically, for a power source with a given power rating, the profile of the tractive effort versus the speed should be a constant 


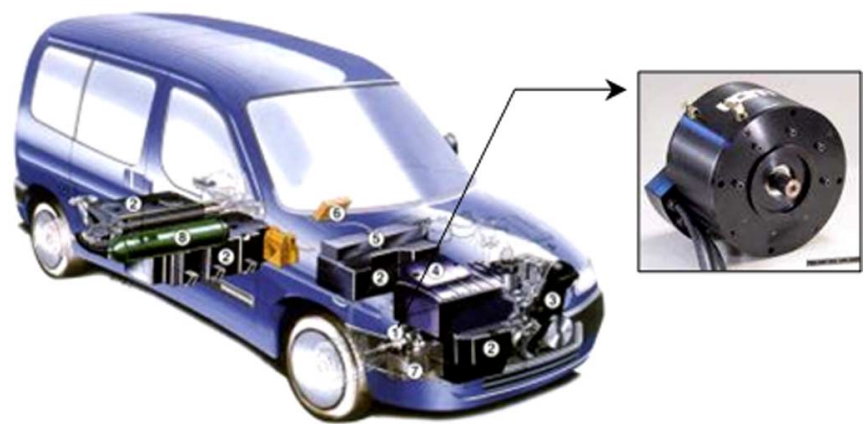

Fig. 4. DC motor in the Hybrid Citroën Berlingo [Citroën].

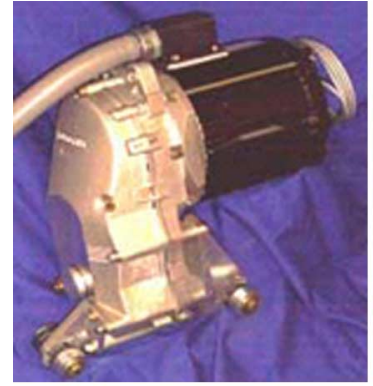

(a)

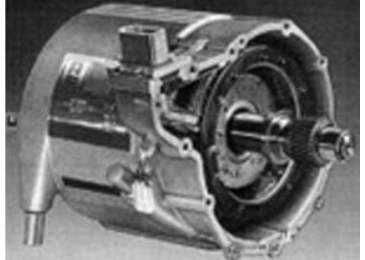

(b)
Fig. 5. Industrial IMs. (a) External view of an IM traction drive [Solectria]. (b) Water-cooled IM [Delco].

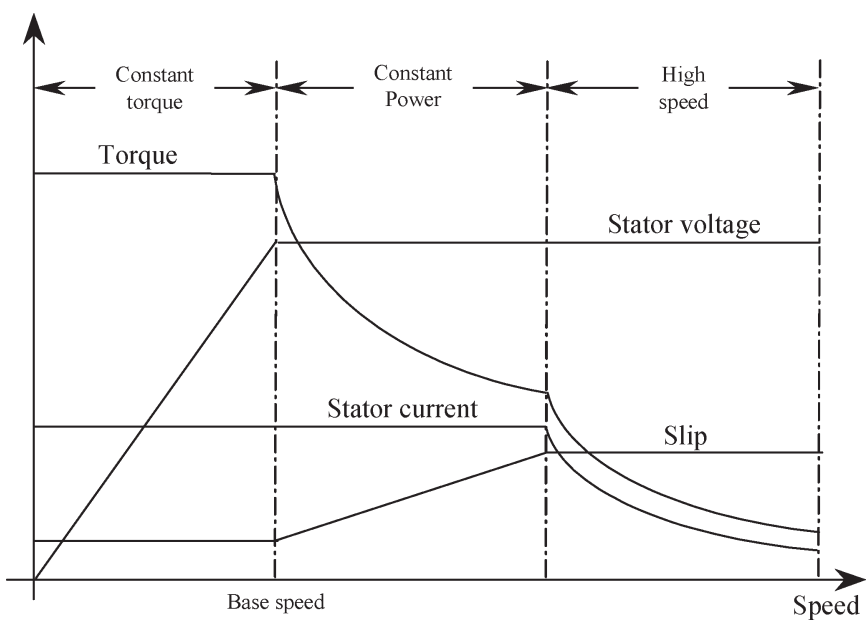

Fig. 6. IM characteristics.

power in the speed range, and then, the tractive effort drops hyperbolically with the increase of the vehicle speed [1], [3]. It should be noted that these characteristics depend on HF.

\section{COMparative STUdy}

\section{A. DC Motors $(D C)$}

DC motors have been prominent in electric propulsion because their torque-speed characteristics suit the traction requirement well, and their speed controls are simple. However, dc motor drives have a bulky construction, low efficiency, low reliability, and higher need of maintenance, mainly due to the presence of the mechanical commutator (brush), even if interesting progress has been made with slippery contacts.
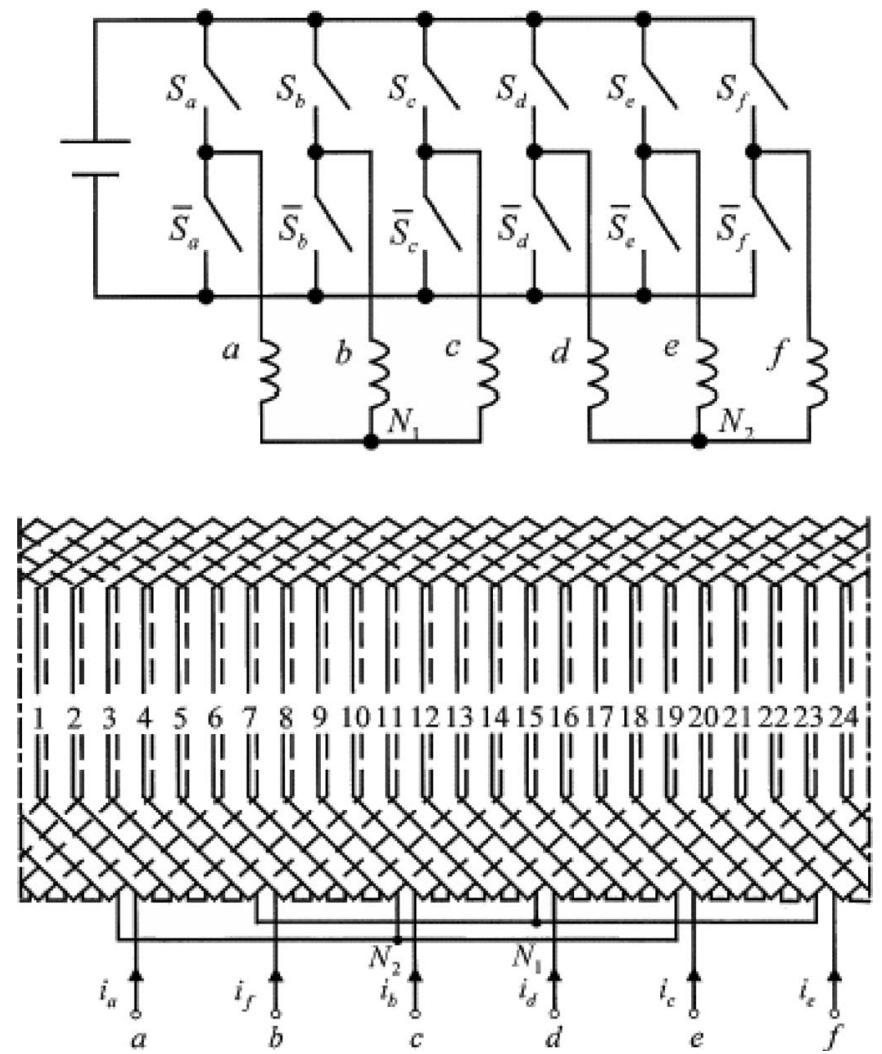

Fig. 7. Inverter-fed six-phase pole-changing IM drive [21].

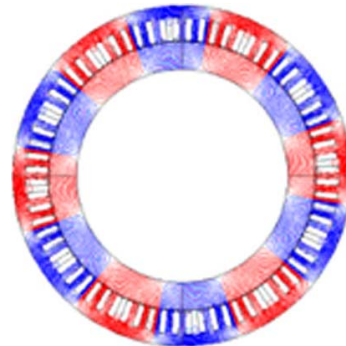

(a)

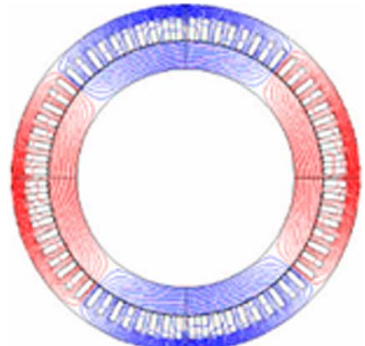

(b)
Fig. 8. Main flux of a pole-changing IM drive [22]. (a) Twelve-pole configuration. (b) Four-pole configuration.

Moreover, the development of rugged solid-state power semiconductors made it increasingly practical to introduce the ac induction and synchronous motor drives that are mature to replace the $\mathrm{dc}$ motor drive in traction applications. In fact, the commutatorless motors are attractive, as high reliability and maintenance-free operation are prime considerations for electric propulsion. Nevertheless, with regard to the cost of the inverter, ac drives are used generally just for higher power. At low power ratings, the dc motor is still more than an alternative. Improvement of existing cars ("reengineering") without changing the mechanical part can be achieved by the new dc chopper power electronics. The commutator, if used in proper operation, is a very rugged "inverter"; therefore, the power electronics circuit can be kept relatively simple and thus at low cost. This is the case of the French automaker PSA Peugeot Citroën, who introduced the HEV version of the well-known 


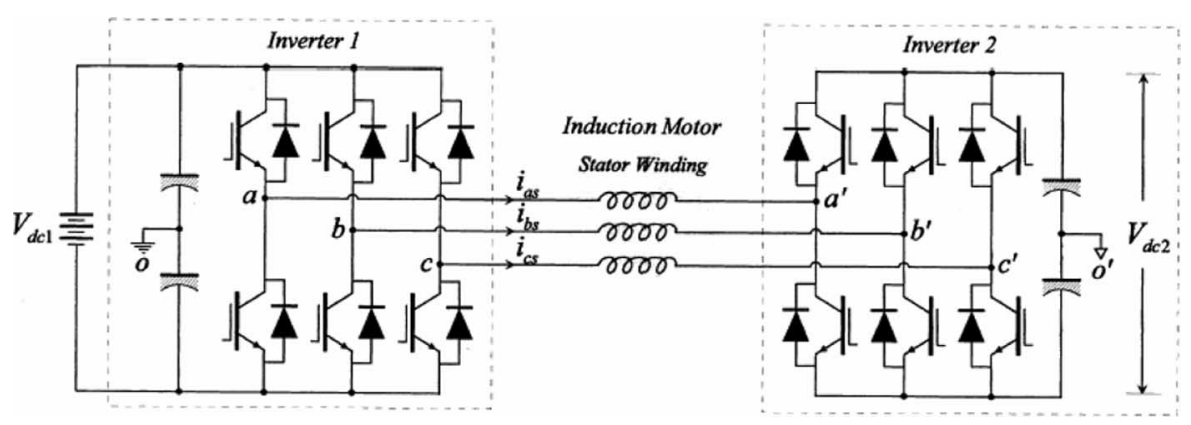

Fig. 9. Dual inverter system [23].

Berlingo, which is called Dynavolt, with a dc motor as electric propulsion (Fig. 4) [12].

\section{B. Induction Motor (IM)}

Cage IMs are widely accepted as the most potential candidate for the electric propulsion of HEVs, owing to their reliability, ruggedness, low maintenance, low cost, and ability to operate in hostile environments. They are particularly well suited for the rigors of industrial and traction drive environments. Today, an IM drive is the most mature technology among various commutatorless motor drives [3], [4]. For illustration, Fig. 5 shows industrial traction IMs.

Fig. 6 shows the typical characteristics of an IM drive. Vector control of IMs can decouple its torque control from field control. Extended speed range operation with a constant power beyond the base speed is accomplished by flux weakening.

However, the presence of a breakdown torque limits its extended constant-power operation. At the critical speed, the breakdown torque is reached. Generally, for a conventional IM, the critical speed is around two times the synchronous one. Any attempt to operate the motor at the maximum current beyond this speed will stall the motor. Moreover, efficiency at a highspeed range may suffer in addition to the fact that IMs efficiency is inherently lower than that of PM motors, due to the absence of rotor winding and rotor copper losses [1].

In general, IM drives were facing a number of drawbacks that pushed them out from the race of HEVs electric propulsion. These drawbacks are mainly high loss, low efficiency, low power factor, and low inverter-usage factor, which is more serious for the high speed, large power motor. Fortunately, these drawbacks are taken into consideration according to the available literature. Some researches propose taking into account these problems in the design step of the IM used for HEVs [13]-[15].

To improve the IM drives efficiency, a new generation of control techniques has been proposed [16], [17]. Some of the proposed techniques are particularly devoted to HEV applications [18], [19], which constitute a progress compared to the study made in [20].

To extend the constant-power region without oversizing the motor (to solve the problem of breakdown torque), the use of a multiphase pole-changing IM drive, especially for traction application, has been proposed (Figs. 7 and 8) [21], [22]. In [21], the key was to propose a new sinusoidal pulsewidth modulation (PWM) strategy in such a way that the two carriers

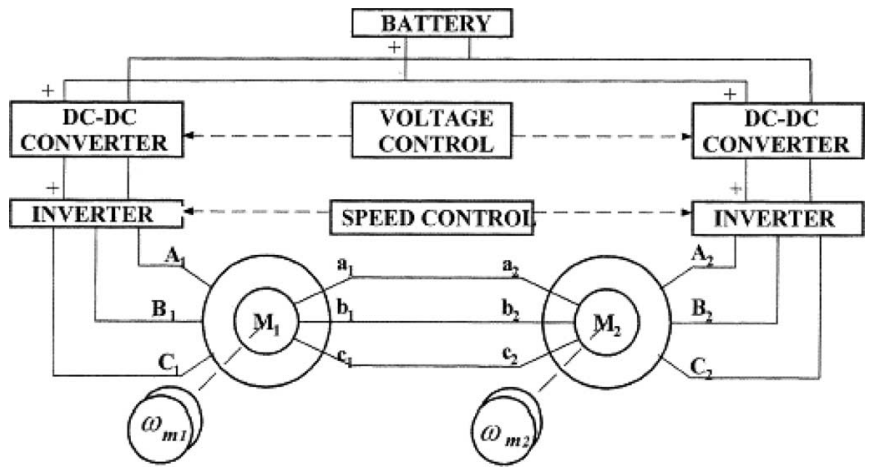

Fig. 10. Doubly fed differential drive layout [24].

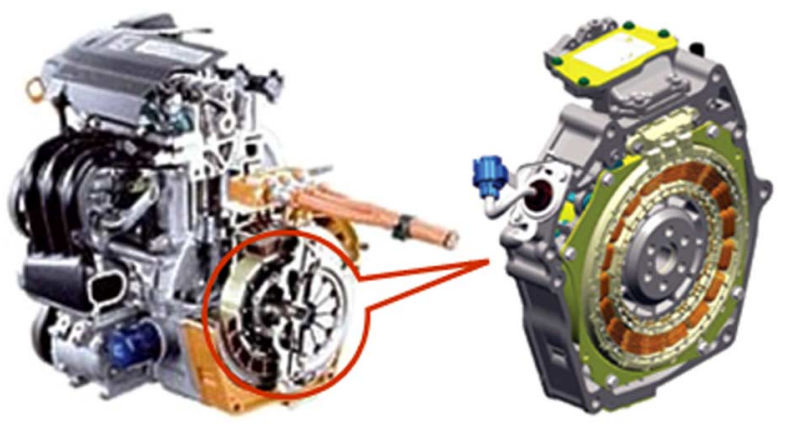

(a)

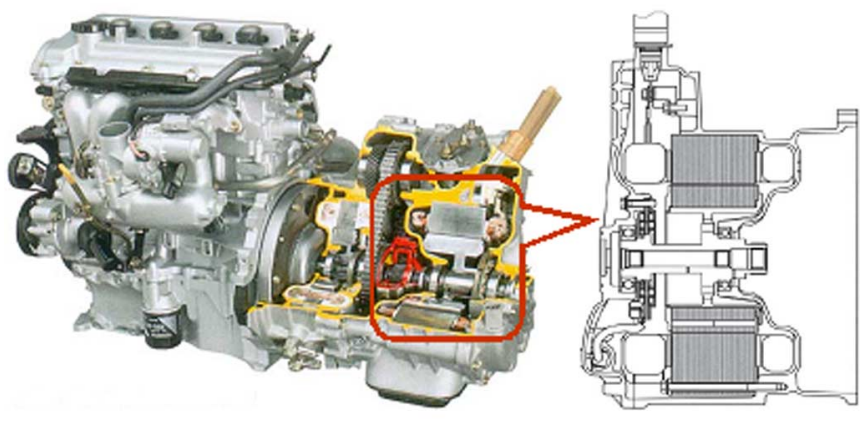

(b)

Fig. 11. Industrial PM synchronous motor. (a) $10-\mathrm{kW}$ motor of the Honda Insight [25]. (b) 50-kW motor of the Toyota Prius [26].

of the six-phase inverter are out of phase during a four-pole operation while they are in phase during a two-pole operation. Another approach to enlarge the constant-power region (up to $10: 1$ ) is to use dual inverters (Fig. 9) [23]. Finally, it should be noticed that certain research works tend to introduce 


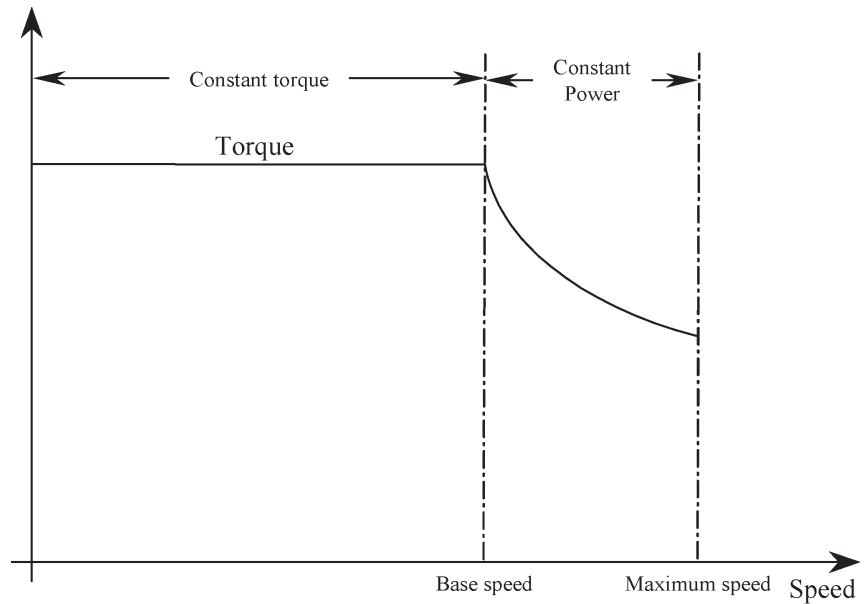

(a)

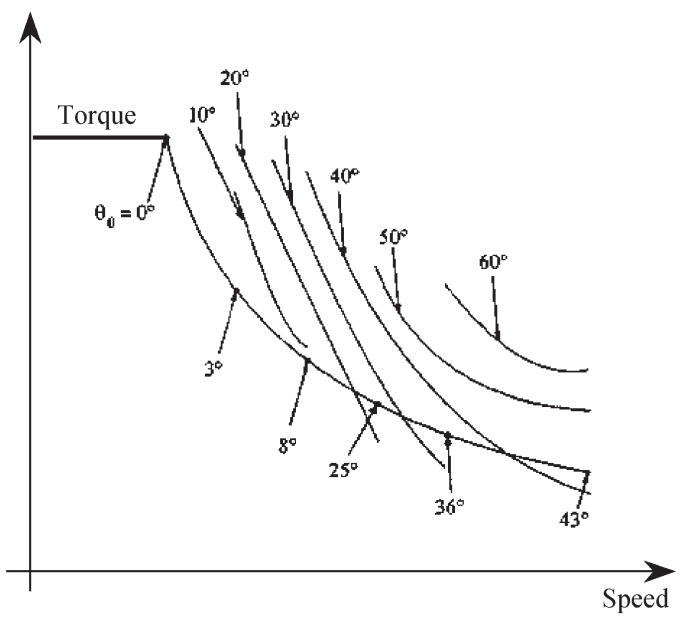

(b)

Fig. 12. Torque-speed characteristic of a PM brushless drive. (a) Typical characteristic. (b) With conduction-angle control.

the doubly fed IM as an electric propulsion, as they have excellent performance at low speeds (Fig. 10) [24].

\section{Synchronous Motor (PM Brushless Motor)}

PM brushless motors are most capable of competing with IMs for the electric propulsion of HEVs. In fact, they are adopted by well-known automaker for their HEVs (Fig. 11). These motors have a number of advantages, including 1) the overall weight and volume are significantly reduced for a given output power (high power density); 2) they have a higher efficiency as mentioned above; and 3 ) heat is efficiently dissipated to the surroundings. However, these motors inherently have a short constant-power region due to their rather limited field weakening capability, resulting from the presence of the PM field (the fixed PM limit their extended speed range) [Fig. 12(a)] [1]. In order to increase the speed range and improve the efficiency of PM brushless motors, the conduction angle of the power converter can be controlled at above the base speed. Fig. 12(b) shows the torque-speed characteristic of a PM brushless motor with a conduction-angle control. The speed range may be extended three to four times over the base speed.
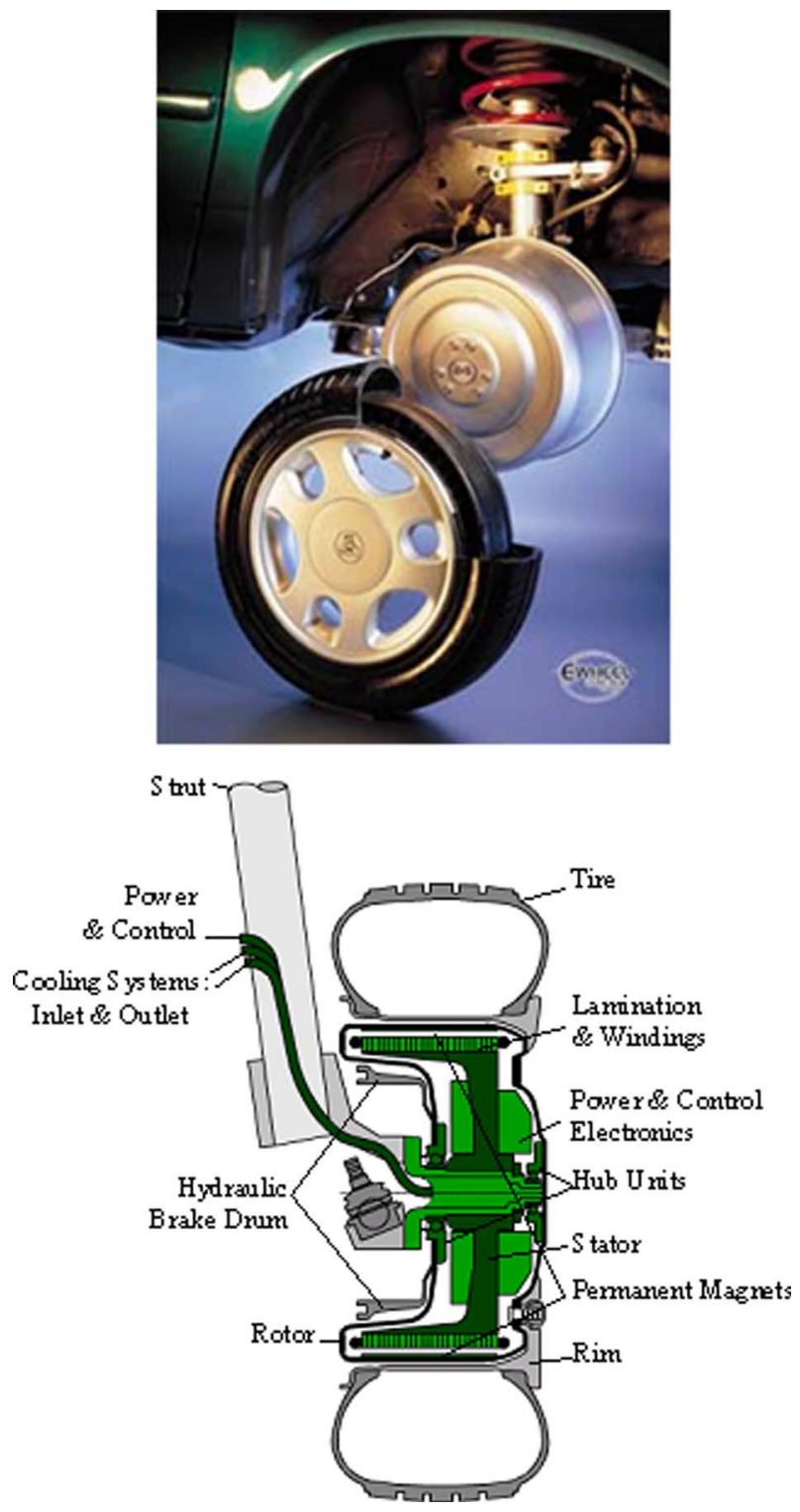

Fig. 13. In-wheel PM brushless motor layout [TM4].

Indeed, in these motors, which are also called PM hybrid motors, an additional field winding is used in such a way that the air-gap field provided by PMs can be weakened during a high-speed constant-power operation by controlling the direction and magnitude of the dc field current. However, at a very high-speed range, the efficiency may drop because of the risk of PMs demagnetization [3], [5].

There are various configurations of the PM brushless motors. Depending on the arrangement of the PM, basically, they can be classified as surface-magnet mounted or buried-magnet mounted, with the latter being the more rugged. The surfacemagnet designs may use fewer magnets, while the buriedmagnet designs may achieve a higher air-gap flux density. Another configuration is the so-called PM hybrid motor, where the air-gap magnetic field is obtained through the combination of PM and field winding. In the broader term, PM hybrid motor may also include the motor whose configuration utilize the combination of PM motor and reluctance motor. PM hybrid motors offer a wider speed range and a higher overall efficiency 


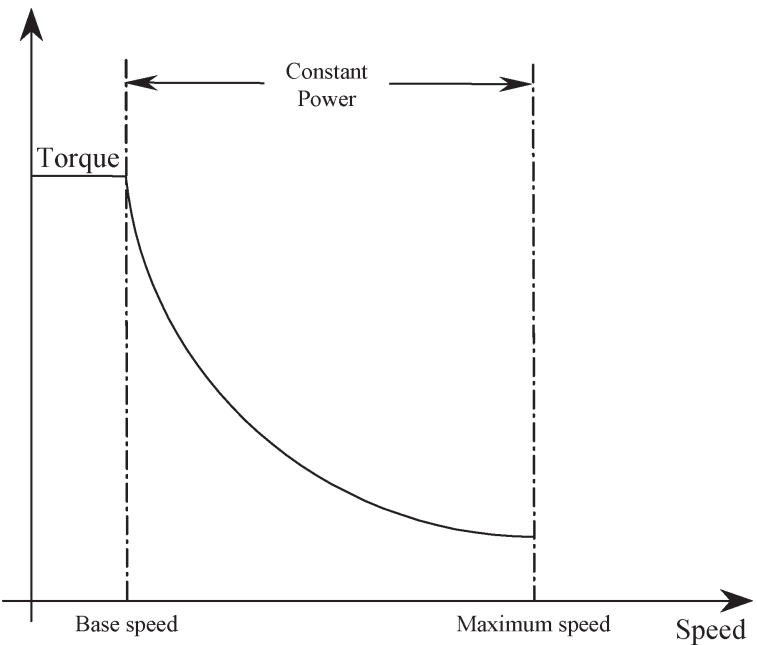

Fig. 14. Typical torque-speed characteristic of an SRM.
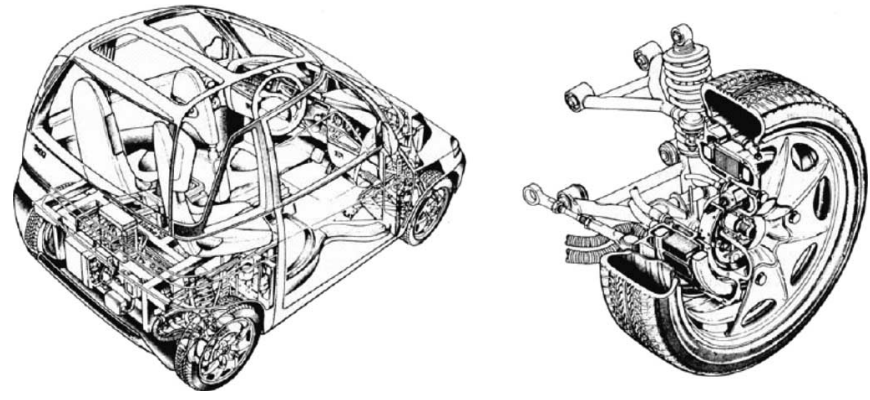

Fig. 15. In wheel SRM in the Fiat "Downtown" [30].

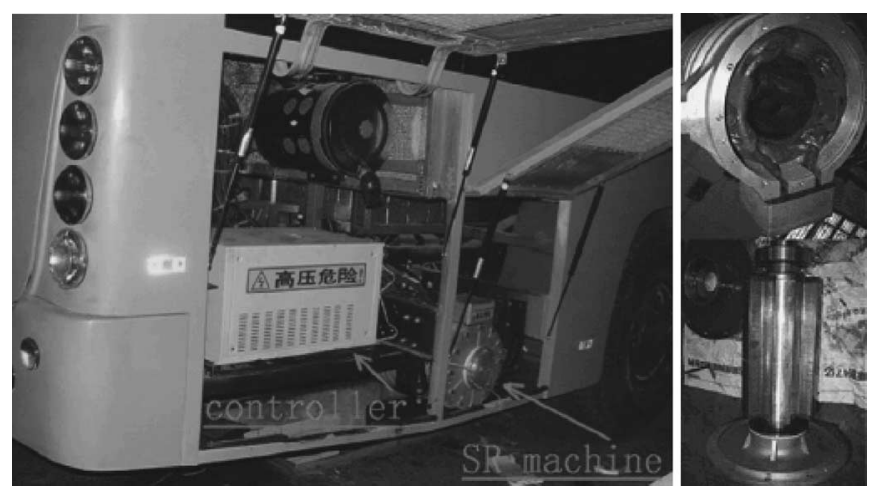

Fig. 16. A 50-kW SRM in an experimental HEV bus [31].

but with a more complex construction [3]. Finally, the PM brushless motor is particularly privileged and suited for the wheel direct-drive motor applications (Fig. 13) [27].

\section{Switched Reluctance Motor (SRM)}

SRMs are gaining much interest and are recognized to have a potential for HEV applications. These motors have definite advantages such as simple and rugged construction, fault-tolerant operation, simple control, and outstanding torque-speed characteristics (Fig. 14). SRM can inherently operate with an extremely long constant-power range. There are, however, several disadvantages, which for many applications outweigh the advantages. Some of these disadvantages are acoustic noise
TABLE I

ELECTRIC PROPUlsion Adopted IN THE AUtomotive INDUSTRY

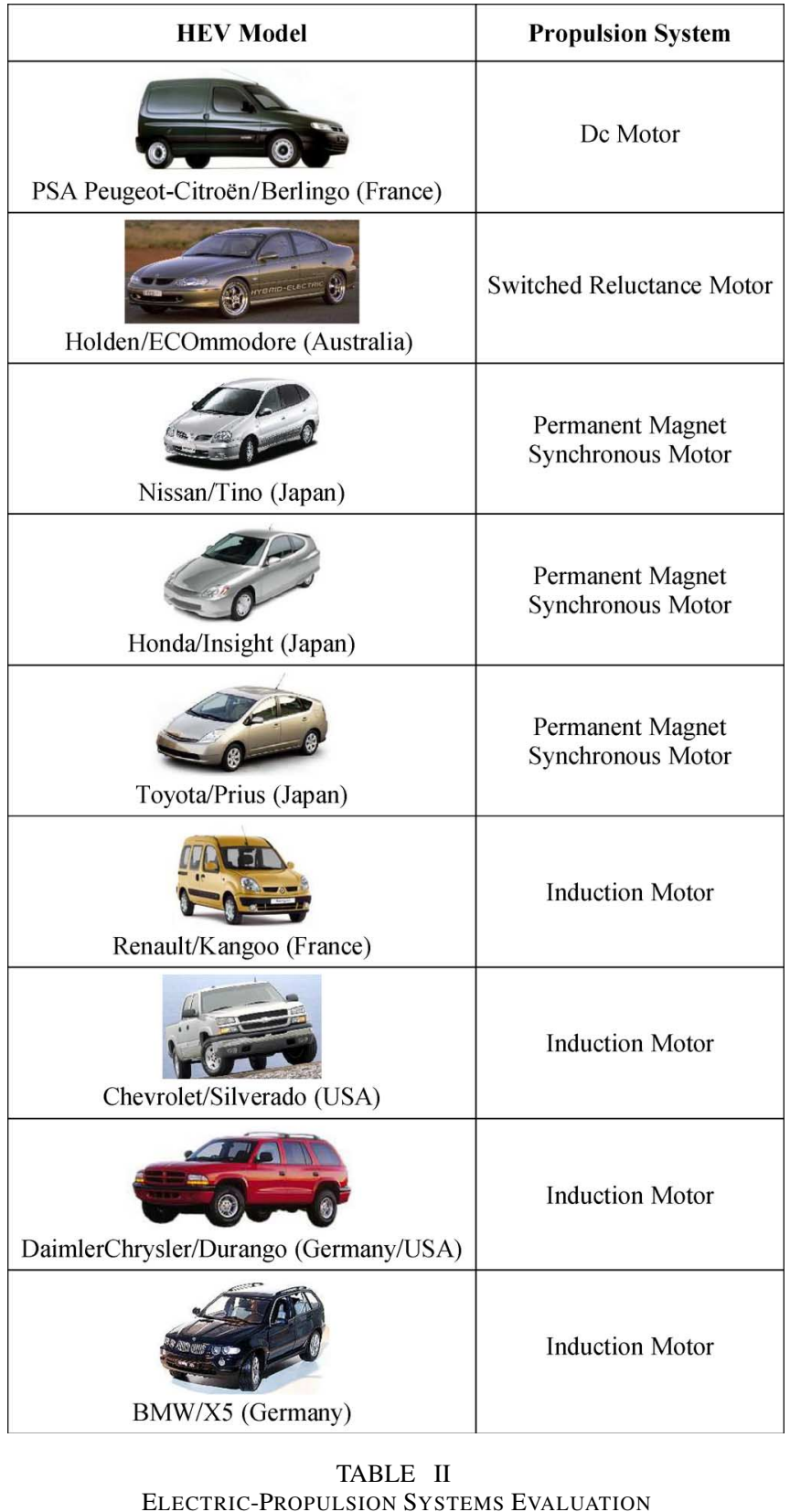

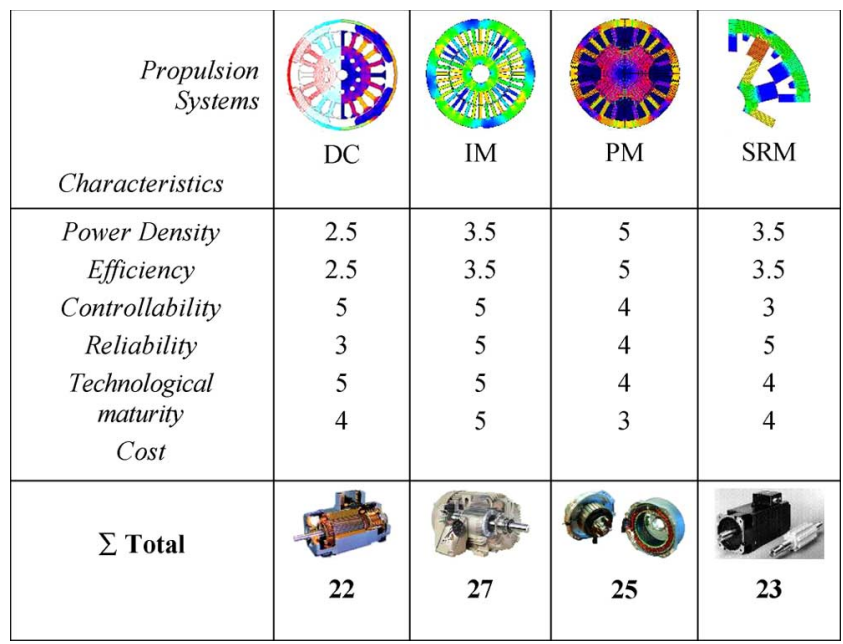




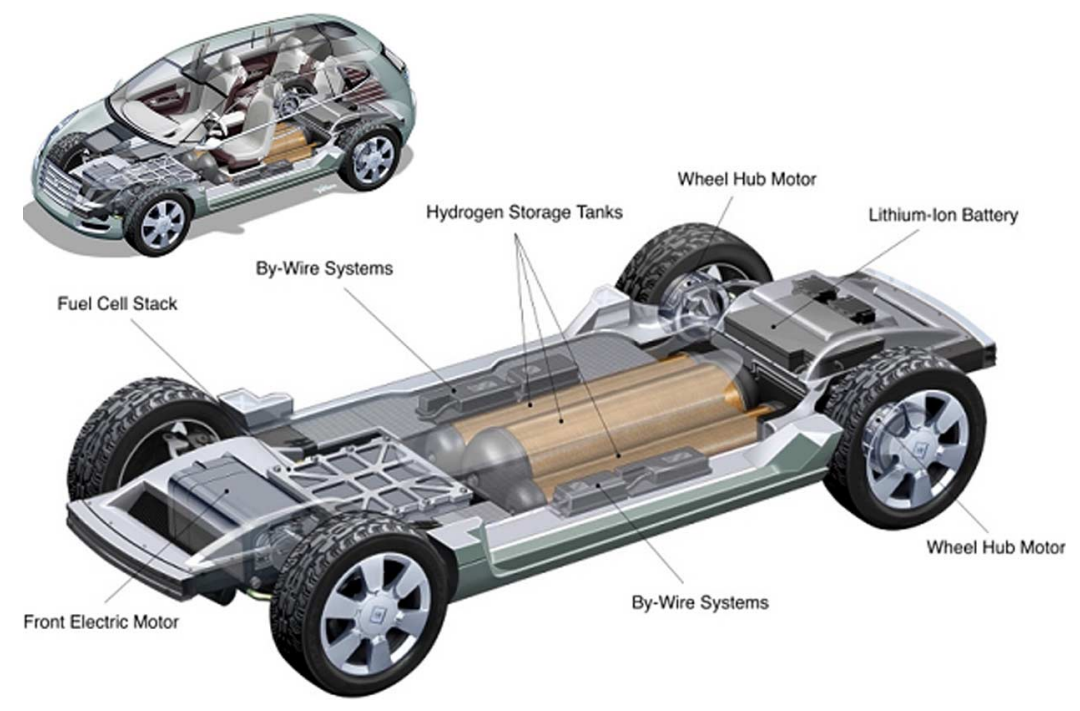

Fig. 17. Sequel concept [GM].

generation, torque ripple, special converter topology, excessive bus current ripple, and electromagnetic-interference (EMI) noise generation. All of the above advantages as well as the disadvantages are quite critical for vehicle applications. Acceptable solutions to the above disadvantages are needed to get a viable SRM-based HEV [28], [29]. Nevertheless, SRM is a solution that is actually envisaged for light and heavy HEV applications (Figs. 15 and 16) [30], [31].

\section{E. Industrial Applications}

Table I briefly reviews the electric propulsion recently adopted in the automotive industry. Other examples corresponding more to HEV concepts are given in [32] and [34].

\section{F. Preliminary Conclusion and Perspectives}

The IM seems to be the most adapted candidate for the electric propulsion of urban HEVs. In fact, this solution is a consensual one, as illustrated by the evaluation summarized in Table II, and based on the main characteristics of the HEV electric propulsion, each of them is graded from one to five points, where five points means the best. Indeed, this evaluation is an update of the one done in [3]. In our comparative study, we have implicitly given the same weight to all the characteristic factors so as to cover a wide range of HEV applications, which are mainly urban HEVs. Otherwise, some of these factors should be weighted according to the application. For example, in [32], the motor choice is determined by three factors: weight, efficiency, and cost. Another example is combat vehicles, where reliability and technological maturity are much more important than efficiency. In some cases, this could lead to another classification.

However, among the aforementioned motor electricpropulsion features, the extended speed range ability and energy efficiency are the two basic characteristics that are influenced by vehicle dynamics and system architecture. Therefore, the selection of traction drives for HEVs demands special attention to these two characteristics. Moreover, the issue of an extended speed range is significant to a vehicle's acceleration

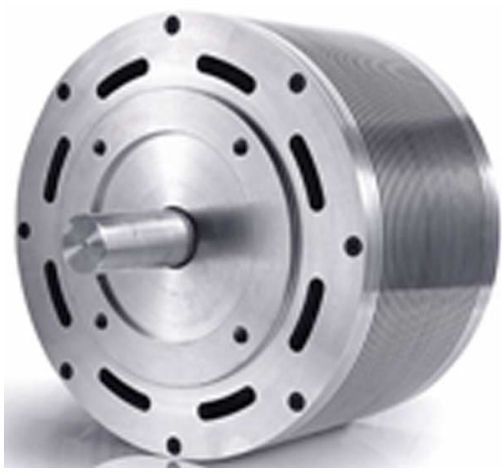

Fig. 18. Symetron IM [33].

performance, which is a design criterion usually determined by the user's demand. However, in real-time driving, the vehicle rarely operates in extreme conditions (i.e., high speed and acceleration).

Thus, the issue of energy efficiency of the system becomes important [1], [3]. From this analysis, a conclusion that should be drawn is that a PM brushless motor is an alternative (Table II). This is why competition remains hard between the induction and PM motors. In this context, some automakers try to combine the advantages of these two motors. In fact, on the GM HEV, which is called Sequel, an IM is used in the vehicle front, and two PM brushless motors are used as wheel hub motors (Fig. 17).

Recently, a new IM technology has been developed for traction application, requiring flat or hub-style motors (pancake or hub motor) (Fig. 18) [33]. The developed motor can produce the torque of a PM motor without using a PM material. Other features include a wide range of constant power, very smooth acceleration, less torque ripple, reduced manufacturing costs, and operation at higher temperatures and higher speed.

\section{SUMMARY}

In this paper, potential candidates for a traction motor for parallel HEVs have been presented and evaluated according to 
the major requirements of an HEV electric-propulsion system. The comparative study has revealed that the IM is the solution that makes the consensus, even if competition remains hard with PM brushless motors. Moreover, this paper consolidates other comparative investigations [32], [34].

\section{REFERENCES}

[1] Z. Rahman et al., "An investigation of electric motor drive characteristics for EV and HEV propulsion systems," presented at the SAE Technical Paper Series, Paper \# 2000-01-3062.

[2] L. Eudy et al., "Overview of advanced technology transportation, 2004 Update," Natl. Renewable Energy Lab., Golden, CO, DOE/GO102004-1849, Aug. 2004.

[3] C. C. Chan, "The state of the art of electric and hybrid vehicles," Proc. IEEE, vol. 90, no. 2, pp. 247-275, Feb. 2002.

[4] T. M. Jahns et al., "Recent advances in power electronics technology for industrial and traction machine drives," Proc. IEEE, vol. 89, no. 6, pp. $963-975$, Jun. 2002.

[5] C. C. Chan et al., "An overview of power electronics in electric vehicles," IEEE Trans. Ind. Electron., vol. 44, no. 1, pp. 3-13, Feb. 1997.

[6] K. Rajashekara, "History of electric vehicles in General Motors," IEEE Trans. Ind. Appl., vol. 30, no. 4, pp. 897-904, Jul./Aug. 1994.

[7] A. Emadi et al., "Topological overview of hybrid electric and fuel cell vehicular power system architectures and configurations," IEEE Trans. Veh. Technol., vol. 54, no. 3, pp. 763-770, May 2005.

[8] S. M. Lukic et al., "Effects of drivetrain hybridization on fuel economy and dynamic performance of parallel hybrid electric vehicles," IEEE Trans. Veh. Technol., vol. 53, no. 2, pp. 385-389, Mar. 2004.

[9] Z. Rahman et al., "A comparison study between two parallel hybrid control concepts," presented at the SAE Technical Paper Series, Paper \# 2000-01-0994.

[10] D. Diallo et al., "A fault-tolerant control architecture for induction motor drives in automotive applications," IEEE Trans. Veh. Technol., vol. 53, no. 6 , pp. $1847-1855$, Nov. 2004.

[11] A. G. Jack et al., "A comparative study of permanent magnet and switched reluctance motors for high-performance fault tolerant applications," IEEE Trans. Ind. Appl., vol. 32, no. 4, pp. 889-895, Jul./Aug. 1996.

[12] G. Dancygier et al., "Motor control law and comfort law in the Peugeot and Citroën electric vehicles driven by a dc commutator motor," in Proc. IEE-Power Electron. and Variable Speed Drives Conf., Sep. 21-23, 1998, pp. 370-374.

[13] T. Wang et al., "Design characteristics of the induction motor used for hybrid electric vehicle," IEEE Trans. Magn., vol. 41, no. 1, pp. 505-508, Jan. 2005.

[14] G. Pugslay et al., "New modeling methodology for induction machine efficiency mapping for hybrid vehicles," in Proc. IEEE Int. Elect. Mach. and Drives Conf., Madison, WI, Jun. 1-4, 2003, vol. 2, pp. 776-781.

[15] D. H. Cho et al., "Induction motor design for electric vehicle using niching genetic algorithm," IEEE Trans. Ind. Appl., vol. 37, no. 4, pp. 994-999, Jul./Aug. 2001

[16] M. E. H. Benbouzid et al., "An efficiency-optimization controller for induction motor drives," IEEE Power Eng. Lett., vol. 18, no. 5, pp. 43-45, May 1998.

[17] — "Fuzzy efficient-optimization controller for induction motor drives," IEEE Power Eng. Lett., vol. 20, no. 10, pp. 43-44, Oct. 2000.

[18] H. D. Lee et al., "Fuzzy-logic-based torque control strategy for paralleltype hybrid electric vehicle," IEEE Trans. Ind. Electron., vol. 45, no. 4, pp. 625-632, Aug. 1998.

[19] B. Kou et al., "Operating control of efficiently generating induction motor for driving hybrid electric vehicle," IEEE Trans. Magn., vol. 41, no. 1, pp. 488-491, Jan. 2005.

[20] G. Brusaglino et al., "Advanced drives for electrically propelled vehicles," in Proc. IEE Colloquium-Elect. Mach. Design All-Electric Hybrid-Elect. Veh., pp. 4/1-4/12.

[21] S. Z. Jiang et al., "Spectral analysis of a new six-phase pole-changing induction motor drive for electric vehicles," IEEE Trans. Ind. Electron., vol. 50, no. 1, pp. 123-131, Feb. 2003.

[22] J. W. Kelly et al., "Control of a continuously operated pole-changing induction machine," in Proc. IEEE Int. Elect. Mach. and Drives Conf., Madison, WI, Jun. 1-4, 2003, vol. 1, pp. 211-217.

[23] J. Kim et al., "Dual-inverter control strategy for high-speed operation of EV induction motors," IEEE Trans. Ind. Electron., vol. 51, no. 2, pp. 312-320, Apr. 2004
[24] M. S. Vicatos et al., "A doubly-fed induction machine differential drive model for automobiles," IEEE Trans. Energy Convers., vol. 18, no. 2, pp. 225-230, Jun. 2003.

[25] K. Aoki et al., "Development of integrated motor assist hybrid system Development of the 'Insight,' a personal hybrid coupe," presented at the SAE Technical Paper Series, Paper \# 2000-01-2216.

[26] H. Endo et al., "Development of Toyota's transaxle for mini-van hybrid vehicles," JSAE Rev., vol. 24, no. 2, pp. 109-116, 2003.

[27] M. Terashima et al., "Novel motors and controllers for high-performance electric vehicle with four in-wheel motors," IEEE Trans. Ind. Electron. vol. 44, no. 1, pp. 28-38, Feb. 1997.

[28] J. Malan et al., "Performance of a hybrid electric vehicle using reluctance synchronous machine technology," IEEE Trans. Ind. Appl., vol. 37, no. 5, pp. 1319-1324, Sep./Oct. 2001.

[29] K. M. Rahman et al., "Advantages of switched reluctance motor applications to EV and HEV: Design and control issues," IEEE Trans. Ind. Appl., vol. 36, no. 1, pp. 111-121, Jan./Feb. 2000.

[30] G. Brusaglino, "Energy management optimization by an auxiliary power source," in dans les Actes du Symp. Véhicules Propres, La Rochelle, France, Nov. 1993, pp. 223-230.

[31] S. Wang et al., "Implementation of 50-kW four-phase switched reluctance motor drive system for hybrid electric vehicle," IEEE Trans. Magn., vol. 41, no. 1, pp. 501-504, Jan. 2005.

[32] J. G. W. West, "DC, induction, reluctance and PM motors for electric vehicles," Power Eng. J., vol. 8, no. 2, pp. 77-88, Apr. 1994.

[33] "Symetron P-2 AC motor technology," AC Induction Motor Design for "Pancake" or "Hub" Motor Applications. [Online]. Available: http:// www.rasertech.com/

[34] L. Chang, "Comparison of ac drives for electric vehicles-A report on expert's opinion survey," IEEE Aerosp. Electron. Syst. Mag., vol. 9, no. 8, pp. 7-11, Aug. 1994

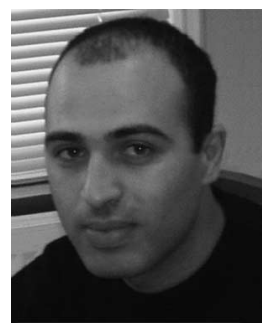

Mounir Zeraoulia (S'04) was born in Yabous, Algeria, in 1975. He received the B.Sc. degree from the University of Batna, Batna, Algeria, in 2000 and the M.Sc. degree from University of Valenciennes, Valenciennes, France, in 2002, all in electronics. He is currently working toward the Ph.D. degree on hybrid electrical vehicle control at the University of Western Brittany, Brest, France.

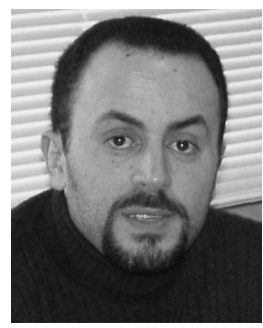

Mohamed El Hachemi Benbouzid (S'92-M'95SM'98) was born in Batna, Algeria, in 1968. He received the B.Sc. degree in electrical engineering from University of Batna, in 1990, the M.Sc. and $\mathrm{Ph} . \mathrm{D}$. degrees, both in electrical and computer engineering, from National Polytechnic Institute, Grenoble, France, in 1991 and 1994, respectively, and the "Habilitation à Diriger des Recherches" degree from University of Picardie "Jules Verne," Picardie, France, in November 2000

He joined the University of Picardie "Jules Verne," where he was an Associate Professor of electrical and computer engineering with the Professional Institute of Amiens. In September 2004, he joined the IUT of Brest, University of Western Brittany, Brest, France, as a Professor of electrical engineering. His main research interests and experience include analysis, design, and control of electric machines, variable-speed drives for traction and propulsion applications, and fault diagnosis of electric machines.

Prof. Benbouzid is an IEEE Senior Member of the Power Engineering, Industrial Electronics, Industry Applications, Power Electronics, and Vehicular Technology Societies. He is an Associate Editor of the IEEE TRANSACTIONS ON ENERGY CONVERSION, the IEEE TRANSACTIONS ON INDUSTRIAL ELECTRONICS, the IEEE TRANSACTIONS ON VehICULAR TECHNOLOGY, and the IEEE/ASME TRANSACTIONS ON MECHATRONICS. 


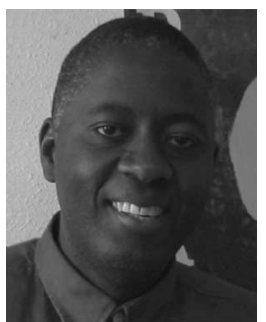

Demba Diallo (M'99-SM'05) was born in Dakar, Senegal, in 1966. He received the M.Sc. and Ph.D. degrees, both in electrical and computer engineering, from the National Polytechnic Institute, Grenoble, France, in 1990 and 1993, respectively, and the "Habilitation à Diriger des Recherches" degree from University of Paris XI, Paris, France, in December 2005.

From 1994 to 1999, he worked as a Research Engineer with the Laboratoire d'Electrotechnique de Grenoble, where he was working on electrical drives and active filters (hardware and software). In 1999, he joined the University of Picardie "Jules Verne," Picardie, France, as an Associate Professor of electrical engineering. In September 2004, he joined the IUT of Cachan, University of Paris XI, Cachan, France, as an Associate Professor of electrical engineering. $\mathrm{He}$ is now with the Laboratoire de Génie Electrique de Paris. His current research interest includes advanced control techniques and diagnosis in the field of ac drives. 